\title{
Valor nutritivo da forragem de genótipos de cereais de inverno de duplo propósito
}

\author{
Gilmar Roberto Meinerz ${ }^{1}$, Clair Jorge Olivo $^{2}$, Renato Serena Fontaneli ${ }^{3}$, Carlos Alberto \\ Agnolin ${ }^{1}$, Roberto Serena Fontaneli ${ }^{4}$, Tiago Horst ${ }^{5}$, Julio Viégas ${ }^{2}$, Cláudia Marques de Bem ${ }^{5}$ \\ 1 Programa de Pós-graduação em Zootecnia, Universidade Federal de Santa Maria (UFSM), 97105-900, Santa Maria, RS, Brasil. \\ 2 Departamento de Zootecnia, UFSM, RS, Brasil. \\ ${ }^{3}$ Embrapa Trigo - Passo Fundo, RS, Brasil. \\ ${ }^{4}$ Universidade de Passo Fundo. \\ 5 Curso de graduação em Zootecnia - UFSM.
}

RESUMO - Esta pesquisa foi conduzida com o objetivo de avaliar o valor nutritivo da forragem de 12 genótipos de seis espécies de cereais de inverno de duplo propósito (forragem e grãos), submetidos ao corte, na região da Depressão Central do Rio Grande do Sul. As espécies e genótipos testados foram: trigo (BRS 277, BRS Guatambu, BRS Tarumã, BRS Umbu); aveia-preta (Agro Zebu, UPFA 21 - Moreninha e Comum); aveia-branca (UPF 18); centeio (BR 1 e BRS Serrano); Cevada (BRS Marciana) e triticale (BRS 148).Os genótipos foram distribuídos em 36 parcelas experimentais, num delineamento experimental inteiramente casualizado, com 12 tratamentos e três repetições. As análises de valor nutritivo e composição mineral foram feitas pelo método da reflectância do infravermelho proximal (NIRS), em amostras do estrato superior a $10 \mathrm{~cm}$ de altura da forragem. Os genótipos de aveia e o trigo BRS Umbu apresentaram os melhores resultados de valor nutritivo. A composição mineral apresentou pequena variabilidade entre os genótipos testados. Os resultados demonstram que os cereais de inverno produzem forragem de elevado valor nutritivo.

Palavras-chave: composição química, integração lavoura-pecuária, NIRS, pastagens anuais

\section{Nutritive value of forage of genotypes of double purpose winter cereals}

\begin{abstract}
The objective of this research was to evaluate the nutritive value of the forage of 12 genotypes of six double purpose (forage and grains) winter cereal species submitted to harvest in the region of Depressão Central in Rio Grande do Sul state. The species and genotypes tested were: wheat (BRS 277, BRS Guatambu, BRS Tarumã and BRS Umbu); black oat (Agro Zebu, UPFA 21 - Moreninha and Commom black-oat); white-oat (UPF 18); rye (BR 1 and BRS Serrano); barley (BRS Marciana); and triticale (BRS 148). The genotypes were distributed in 36 experimental plots in completely randomized experimental design, with 12 treatments and three replications. Analysis of nutritive value and mineral composition were performed by the near infrared spectroscopy (NIRS) in samples of stratum greater than 10 $\mathrm{cm}$ height of forage. Oat genotypes and BRS Umbu wheat presented the best nutritive value results. Mineral composition presented small variability among the genotypes tested. The results demonstrate that winter cereals produce high nutritive value forage.
\end{abstract}

Key Words: annual pastures, chemical composition, livestock-crop production system, NIRS

\section{Introdução}

Ocultivo de cereais de inverno, como a aveia (Avena spp.), o trigo (Triticum sativum L.), o centeio (Secale cereale L.), a cevada (Hordeum vulgare L.) e o triticale (X Triticosecale Wittmack) ocupa aproximadamente $35 \%$ das áreas destinadas à agricultura no mundo (Phillips et al., 1996). Na região sul do Brasil, estes cereais são cultivados em sistemas de integração lavoura-pecuária, com duplo propósito de utilização, fornecendo forragem verde de forma precoce e ainda produzindo grãos (Del Duca \& Fontaneli, 1995).
A exploração destes sistemas de produção tem como objetivo otimizar o uso da terra, da infra-estrutura e da mãode-obra, permitindo diversificar e verticalizar a produção (Mello et al., 2004). Dentro desse conceito, as áreas de lavoura dão suporte à pecuária por meio da produção de alimento para o animal, seja na forma de grãos, silagem e feno ou de pastejo direto, aumentando a capacidade de suporte da propriedade, permitindo a venda de animais na entressafra e proporcionando melhor distribuição de receita durante o ano (Mello et al., 2004). Porém, sua utilização depende de sólidos conhecimentos nas áreas de agricultura 
e pecuária, para que uma atividade não seja beneficiada em detrimento da outra.

Neste sentido, a produção de forragem de baixo custo e elevado valor nutritivo no período outonal, quando as espécies de verão já completaram seu ciclo e as de inverno ainda não estão satisfatoriamente desenvolvidas, é um indicativo da importância deste sistema para a produção animal (Scheffer-Basso et al., 2004).

A quantidade e a qualidade da forragem produzida pelos cereais de inverno são determinadas por diversos fatores, como a variabilidade entre as espécies, entre genótipos de mesma espécie e sua adaptabilidade às diferentes condições edafoclimáticas (Bruckner \& Hanna, 1990). Considerando essa variabilidade, a avaliação dos genótipos é uma estratégia fundamental para a exploração das potencialidades de cada espécie. Assim, objetivou-se com este experimento avaliar o valor nutritivo da forragem de genótipos de cereais de inverno de duplo propósito na região da Depressão Central do Rio Grande do Sul.

\section{Material de Métodos}

O experimento foi conduzido no Laboratório de Bovinocultura de Leite da UFSM (Universidade Federal de Santa Maria), localizado na região fisiográfica denominada Depressão Central do Rio Grande do Sul, com altitude de $95 \mathrm{~m}$, latitude $29^{\circ} 43^{\prime}$ Sul e longitude $53^{\circ} 42^{\prime}$ Oeste, entre março e outubro de 2008. O solo da área experimental é classificado como Argissolo Vermelho distrófico arênico, pertencente à unidade de mapeamento São Pedro (Embrapa, 1999) e o clima da região é o Cfa (subtropical úmido), conforme classificação de Köppen (Moreno, 1961). As médias de temperatura e a precipitação pluviométrica do período foram de $14,86^{\circ} \mathrm{C}$ e $985,2 \mathrm{~mm}$ (168,89 mm mensais), similares às médias climáticas normais da região.

Foram testadas 12 cultivares de seis espécies de cereais de inverno de duplo propósito de utilização: trigo (BRS 277, BRS Guatambu, BRS Tarumã, BRS Umbu); aveia-preta (Agro Zebu, UPFA 21 - Moreninha e Comum); aveia-branca (UPF 18); centeio (BR 1 e BRS Serrano); Cevada (BRS Marciana) e triticale (BRS 148).

A área experimental foi dividida em 36 parcelas experimentais, com dimensões de $5 \mathrm{~m}$ de comprimento e $3 \mathrm{~m}$ de largura, com espaçamento de $1 \mathrm{~m}$. Os dados da análise do solo foram os seguintes: índice SMP $=5,2 ; \mathrm{P}=2,2 \mathrm{mg} / \mathrm{dm}$; $\mathrm{K}=0,12 \mathrm{cmol}_{\mathrm{C}} / \mathrm{dm}^{3} ; \mathrm{Al}^{3+}=2,7 \mathrm{cmol}_{\mathrm{C}} / \mathrm{dm}^{3} ; \mathrm{Ca}^{2+}=3,1 \mathrm{cmol}_{\mathrm{C}} / \mathrm{dm}^{3}$; $\mathrm{Mg}=2^{+} 1,5 \mathrm{cmol}_{\mathrm{c}} / \mathrm{dm}^{3} ; \mathrm{MO}=2,3 \%$; saturação de bases = $30,0 \%$; e saturação por alumínio $=36 \%$. A semeadura foi feita em 10 de abril, manualmente em linhas com espaçamento de $17 \mathrm{~cm}$ e com sementes provenientes do Centro Nacional de Pesquisa de Trigo (CNPT-EMBRAPA), em Passo Fundo, Rio Grande do Sul. Trinta dias antes da semeadura, foi realizada a correção da acidez, conforme a análise do solo, com a aplicação de calcário dolomítico do tipo Filler, incorporado mediante escarificação do solo. As adubações potássica e fosfórica foram feitas na semeadura conforme as recomendações da Comissão de Química e Fertilidade do Solo - RS/SC (2004), individualmente para cada espécie, em toda a área da parcela. A adubação nitrogenada $(120$ kg/ha de $\mathrm{N}$ ), a base de uréia, foi dividida igualmente em três aplicações. A primeira foi realizada 30 dias após a emergência das plantas, por ocasião do perfilhamento e as aplicações restantes foram feitas após o primeiro e o segundo cortes.

As forrageiras foram submetidas ao corte ao atingirem entre 25 e $30 \mathrm{~cm}$ de altura (Fontaneli et al., 2009). Neste ponto foram coletadas as amostras e, posteriormente, a área total da parcela foi cortada, com o objetivo de simular o pastejo, buscando-se manter uma altura do resíduo póscorte de 7 a $10 \mathrm{~cm}$ (Fontaneli et al., 2009). Os cortes foram repetidos sempre que as espécies atingiam a altura indicada, até que as plantas apresentassem o primeiro nó, que corresponde ao meristema apical, com $10 \mathrm{~cm}$ de altura, aproximadamente. A partir desta condição foi realizado o diferimento, cessando-se os cortes e permitindo o desenvolvimento final das culturas.

Para determinação do valor nutritivo da forragem, foram coletadas amostras da porção situada acima de $10 \mathrm{~cm}$ de altura das forragens, em cinco locais diferentes de cada parcela. As amostras foram pesadas para determinação da massa de forragem deste estrato, sendo retiradas duas subamostras, uma das quais foi seca em estufa com circulação forçada de ar a $55^{\circ} \mathrm{C}$ até peso constante, moída em moinho tipo Willey, com peneira de $1 \mathrm{~mm}$, identificadas e armazenadas. A outra subamostra foi utilizada para determinação da composição estrutural, fazendo-se manualmente a separação da lâmina foliar, colmo + bainha e material senescente. Estes componentes foram secos em estufa para a determinação dos teores de matéria seca. A composição química foi determinada pelo método de reflectância do infravermelho proximal - NIRS (Tabela 1), descrito por Fontaneli et al. (2002). Os parâmetros estimados foram: proteína bruta (PB), fibra insolúvel em detergente neutro (FDN), fibra insolúvel em detergente ácido (FDA), digestibilidade estimada da matéria seca (DMS) e os minerais, cálcio (Ca), fósforo (P), magnésio (Mg) e potássio (K).

O delineamento experimental foi o inteiramente casualizado, com 12 tratamentos (genótipos), três repetições, com medidas repetidas no tempo (cortes). Os dados foram submetidos à análise de variância e as médias comparadas entre si pelo teste de Tukey ao nível de 5\% de probabilidade. 
Tabela 1 - Variáveis da equação de validação das análises de valor nutritivo pelo método da espectroscopia do infravermelho proximal (NIRS)

\begin{tabular}{|c|c|c|c|c|c|c|c|c|}
\hline Componente & $\begin{array}{c}\text { No } \\
\text { amostras }\end{array}$ & $\begin{array}{l}\text { Média } \\
(\%)\end{array}$ & $\begin{array}{c}\text { Desvio-padrão } \\
(\%)\end{array}$ & EPC & $\mathrm{R}^{2}$ & EPVC & Equação & $\begin{array}{c}\mathrm{R}^{2} \\
\text { Validação }\end{array}$ \\
\hline Proteína bruta & 581 & 10,76 & 4,79 & 0,62 & 0,99 & 0,70 & $y=0,9801 x+0,1882$ & 0,98 \\
\hline Fibra em detergente neutro & 786 & 65,71 & 9,10 & 2,94 & 0,91 & 3,21 & $y=0,9327 x+4,5217$ & 0,89 \\
\hline Fibra em detergente ácido & 797 & 33,26 & 6,62 & 1,58 & 0,96 & 1,65 & $y=0,9703 x+0,9867$ & 0,93 \\
\hline Calcio & 497 & 0,37 & 0,31 & 0,06 & 0,86 & 0,06 & $\mathrm{y}=0,9225 \mathrm{x}+0,0407$ & 0,82 \\
\hline Fósforo & 547 & 0,20 & 0,08 & 0,03 & 0,84 & 0,04 & $\mathrm{y}=0,8614 \mathrm{x}+0,0319$ & 0,83 \\
\hline Potássio & 502 & 1,89 & 0,98 & 0,22 & 0,95 & 0,23 & $\mathrm{y}=0,9587 \mathrm{x}+0,1005$ & 0,93 \\
\hline Magnésio & 515 & 0,24 & 0,05 & 0,03 & 0,72 & 0,04 & $\mathrm{y}=0,6936 \mathrm{x}+0,0667$ & 0,71 \\
\hline
\end{tabular}

EPC = erro-padrão de calibração; coeficiente de determinação $\left(\mathrm{R}^{2}\right)$; e EPVC = erro-padrão de validação cruzada.

Os dados foram submetidos à análise de correlação pelo coeficiente de Pearson. O teste de contrastes foi utilizado para comparar as espécies.

\section{Resultados e Discussão}

No decorrer do período de avaliação, foram realizados três cortes, com intervalos de 16 a 38 dias (Tabela 2). Os genótipos mais precoces e que permitiram menor intervalo entre os cortes foram o triticale BRS 148 e o centeio BR1, mostrando-se promissores para utilização em curtos períodos de carência de forragem. Para a cevada foi observado comportamento similar, embora sendo mais tardia no terceiro corte. Os maiores valores médios de massa de forragem foram obtidos com os trigos, as aveias e o centeio BRS Serrano. Em relação à composição estrutural das forragens, foram observadas diferenças entre as espécies e os genótipos estudados. O trigo BRS Tarumã e o centeio BRS Serrano apresentaram os maiores percentuais médios de lâminas foliares, não diferindo, no entanto, dos demais trigos, das aveias branca e preta Comum, da cevada e do centeio BRS Serrano.

Os percentuais de colmo e bainha tiveram elevada variabilidade no primeiro corte, com valores baixos para os trigos BRS Tarumã, BRS Umbu, BRS 277 e o centeio BRS Serrano. Considerando os valores médios desta variável, há similaridade entre os genótipos. Para o material senescente, observa-se que os genótipos que apresentaram menores percentuais para esta variável foram aqueles com valores maiores de lâminas foliares. Essa associação pode ser confirmada pela correlação encontrada $(r=-0,30$; $\mathrm{P}=0,001)$. Nesta situação, preconiza-se que os intervalos entre cortes sejam mais curtos, permitindo alcançar máxima taxa média de crescimento, sem elevar as taxas de senescência (Parsons et al., 1988).

Os teores de proteína bruta foram similares entre o primeiro e o segundo cortes, com teores superiores a 20\%, com declínio no terceiro corte (Tabela 3), confirmando as afirmações feitas por Bogdan (1977) de que ocorre redução na porcentagem de $\mathrm{PB}$ com o avanço do estádio de desenvolvimento das plantas forrageiras. A exceção a esta tendência foi o trigo BRS Umbu, que apresentou elevação no teor de PB do primeiro para o segundo corte.

Esse comportamento pode ser explicado, em parte, pelo menor intervalo entre cortes, observado para o referido genótipo neste período e pela correlação negativa encontrada entre proteína bruta e intervalo entre cortes $(\mathrm{r}=-0,44 ; \mathrm{P}=0,0072)$. Este menor intervalo entre cortes, possivelmente permitiu maior participação de brotações jovens, que apresentam teores maiores de PB (Van Soest, 1994). Comparando-se as espécies em todos os cortes, a aveia apresentou valores mais elevados em relação ao trigo, ao centeio, e semelhantes à cevada e ao triticale. Os teores obtidos são superiores aos relatados por Cecato et al. (2001), que, avaliando genótipos de aveia submetidos a dois cortes no norte do estado do Paraná, observaram valores médios entre 15,94 e 19,66\% de PB. Nesta região, Hastenpflug (2009), avaliando genótipos de trigo submetidos a dois cortes, observou valores médios entre 20,12 e 25,09\% de PB, semelhantes aos observados nos primeiros dois cortes do presente trabalho.

Na média, os porcentuais de PB foram superiores a $19 \%$, sendo que os teores maiores foram obtidos com as aveias, os trigos BRS Tarumã e BRS Umbu e os genótipos mais precoces (triticale, cevada e centeio BR 1 ). Roso et al. (2000) encontraram valores médios de 20,3\% de PB para a mistura de aveia-preta e azevém sob pastejo, que são as forrageiras de inverno mais utilizadas no estado do Rio Grande do Sul.

Na média, as aveias apresentaram teores mais baixos de FDN. Comparando-se as espécies, os maiores valores de FDN foram observados nos trigos e os menores nas aveias (Tabela 3). No primeiro corte, foram observadas poucas diferenças entre os genótipos, embora tenham sido verificadas diferenças significativas na composição estrutural da forragem (Tabela 2). 
Tabela 2 - Intervalo de cortes, massa de forragem e componentes estruturais em genótipos de espécies de cereais de inverno com duplo propósito submetidos ao corte

\begin{tabular}{|c|c|c|c|c|c|c|c|c|c|c|}
\hline \multirow[t]{2}{*}{ Espécie } & \multirow[t]{2}{*}{ Genótipo } & \multicolumn{2}{|c|}{ 1으 corte } & \multicolumn{2}{|c|}{$2^{o}$ corte } & \multicolumn{2}{|c|}{$3^{\text {o }}$ corte } & \multicolumn{2}{|c|}{ Total/média } & \multirow[t]{2}{*}{ CV (\%) } \\
\hline & & Dias & kg/ha & Dias & $\mathrm{kg} / \mathrm{ha}$ & Dias & $\mathrm{kg} / \mathrm{ha}$ & Dias & kg/ha & \\
\hline & \multicolumn{10}{|c|}{ Massa de forragem (kg/ha de MS) } \\
\hline Triticale & BRS 148 & 40 & 729ab & 22 & 803de & 22 & $904 \mathrm{bc}$ & 84 & $812 \mathrm{~cd}$ & 17,45 \\
\hline Cevada & BRS Marciana & 42 & 755ab & 22 & 723de & 30 & $958 \mathrm{bc}$ & 94 & $812 \mathrm{~cd}$ & \\
\hline \multirow[t]{2}{*}{ Centeio } & BR 1 & 40 & $585 b$ & 22 & $701 \mathrm{e}$ & 22 & $862 \mathrm{c}$ & 84 & $716 \mathrm{~d}$ & \\
\hline & BRS Serrano & 57 & $635 b$ & 34 & $1753 a b$ & 38 & 1064 abc & 119 & $1151 \mathrm{ab}$ & \\
\hline Aveia-branca & UPF 18 & 53 & 768ab & 28 & 1073 cde & 23 & 1289abc & 104 & $1044 b c$ & \\
\hline \multirow[t]{3}{*}{ Aveia-preta } & UPFA-21 Moreninha & 55 & 751ab & 22 & 1375abcd & 31 & 1238abc & 108 & $1121 \mathrm{ab}$ & \\
\hline & Agro-zebu & 55 & $1009 a$ & 23 & 1191bcde & 30 & $1461 \mathrm{ab}$ & 108 & $1220 \mathrm{ab}$ & \\
\hline & Comum & 54 & $805 a b$ & 24 & 1123bcde & 32 & $1175 a b c$ & 110 & $1034 b c$ & \\
\hline \multirow[t]{5}{*}{ Trigo } & BRS 277 & 72 & 809ab & 22 & $1530 a b c$ & 28 & 965bc & 122 & $1101 \mathrm{abc}$ & \\
\hline & BRS Guatambu & 70 & $1053 a$ & 23 & 357abcde & 28 & 1334abc & 122 & $1248 a b$ & \\
\hline & BRS Tarumã & 70 & $636 b$ & 23 & $1882 \mathrm{a}$ & 34 & $1610 \mathrm{a}$ & 127 & $1376 \mathrm{a}$ & \\
\hline & BRS Umbu & 60 & $730 \mathrm{ab}$ & 16 & 948 cde & 28 & $1400 \mathrm{abc}$ & 104 & $1026 \mathrm{bc}$ & \\
\hline & \multicolumn{10}{|c|}{ Lâminas foliares (\% da massa de forragem) } \\
\hline Triticale & BRS 148 & 40 & $64,98 f$ & 22 & $51,23 c$ & 22 & $57,05 a b c$ & 84 & $57,75 d$ & 7,48 \\
\hline Cevada & BRS Marciana & 42 & $65,10 \mathrm{f}$ & 22 & $71,48 a b$ & 30 & $66,91 \mathrm{ab}$ & 92 & $67,83 a b c$ & \\
\hline \multirow[t]{2}{*}{ Centeio } & BR 1 & 40 & 75,49 de & 22 & $65,35 a b c$ & 22 & $60,66 a b c$ & 84 & $67,16 \mathrm{abc}$ & \\
\hline & BRS Serrano & 57 & $98,93 \mathrm{a}$ & 34 & $59,76 \mathrm{bc}$ & 38 & $60,67 \mathrm{abc}$ & 119 & $73,12 \mathrm{a}$ & \\
\hline Aveia-branca & UPF 18 & 53 & $76,75 \mathrm{~cd}$ & 28 & $70,49 a b$ & 23 & $68,35 a$ & 104 & $71,86 a b$ & \\
\hline \multirow[t]{3}{*}{ Aveia-preta } & UPFA-21 Moreninha & 55 & $86,82 b$ & 22 & $61,04 \mathrm{abc}$ & 31 & $44,59 c$ & 108 & 64,15 bcd & \\
\hline & Agro-zebu & 55 & $69,10 \mathrm{ef}$ & 23 & $60,74 \mathrm{abc}$ & 30 & 52,99abc & 108 & $60,94 \mathrm{~cd}$ & \\
\hline & Comum & 54 & 74,35 de & 24 & $68,36 \mathrm{ab}$ & 32 & $62,90 \mathrm{abc}$ & 110 & $68,54 \mathrm{abc}$ & \\
\hline \multirow[t]{4}{*}{ Trigo } & BRS 277 & 72 & $96,44 \mathrm{a}$ & 22 & $68,62 \mathrm{ab}$ & 28 & $51,32 \mathrm{abc}$ & 122 & $72,12 \mathrm{ab}$ & \\
\hline & BRS Guatambu & 70 & $83,86 \mathrm{bc}$ & 23 & $70,82 \mathrm{ab}$ & 28 & $60,50 \mathrm{abc}$ & 122 & $71,72 \mathrm{ab}$ & \\
\hline & BRS Tarumã & 70 & $98,88 a$ & 23 & $76,20 \mathrm{a}$ & 34 & $51,32 \mathrm{abc}$ & 127 & $74,44 a$ & \\
\hline & BRS Umbu & 60 & $98,47 \mathrm{a}$ & 16 & $70,06 \mathrm{ab}$ & 28 & $44,20 \mathrm{a}$ & 104 & $70,91 \mathrm{ab}$ & \\
\hline \multicolumn{11}{|c|}{ Colmo + bainha (\% da massa de forragem) } \\
\hline Triticale & BRS 148 & 28 & 23,83ab & 22 & $37,55 a$ & 22 & $29,97 \mathrm{~cd}$ & 84 & $30,45 a$ & 21,53 \\
\hline Cevada & BRS Marciana & 31 & $22,51 \mathrm{ab}$ & 22 & $18,77 \mathrm{bc}$ & 30 & 31,60bcd & 92 & $24,29 a b$ & \\
\hline \multirow[t]{2}{*}{ Centeio } & BR 1 & 28 & $17,52 \mathrm{bcd}$ & 22 & $30,41 \mathrm{ab}$ & 22 & 33,56bcd & 84 & $27,16 a b$ & \\
\hline & BRS Serrano & 40 & $0,12 \mathrm{~g}$ & 34 & $30,40 \mathrm{ab}$ & 38 & 36,55bcd & 119 & $22,35 \mathrm{ab}$ & \\
\hline Aveia-branca & UPF 18 & 35 & 14,59 cde & 28 & 23,34abc & 23 & $25,68 d$ & 104 & $21,20 b$ & \\
\hline Aveia-preta & UPFA-21 Moreninha & 36 & 7,81ef & 22 & $28,47 a b c$ & 31 & $49,27 a$ & 108 & $28,52 \mathrm{ab}$ & \\
\hline & Agro-zebu & 36 & $25,38 \mathrm{a}$ & 23 & $24,38 a b c$ & 30 & $31,09 \mathrm{~cd}$ & 108 & $26,95 \mathrm{ab}$ & \\
\hline & Comum & 37 & $19,26 a b c$ & 24 & $23,38 \mathrm{abc}$ & 32 & $31,62 \mathrm{~cd}$ & 110 & $24,75 \mathrm{ab}$ & \\
\hline Trigo & BRS 277 & 41 & $2,92 \mathrm{fg}$ & 22 & $22,72 \mathrm{abc}$ & 28 & $47,05 a$ & 122 & $24,23 a b$ & \\
\hline & BRS Guatambu & 41 & 12,05 de & 23 & $20,97 b c$ & 28 & $38,74 \mathrm{bcd}$ & 122 & $23,92 \mathrm{ab}$ & \\
\hline & BRS Tarumã & 42 & $0,17 \mathrm{~g}$ & 23 & $14,28 c$ & 34 & $51,63 a$ & 127 & $22,03 \mathrm{ab}$ & \\
\hline & BRS Umbu & 35 & $0,52 \mathrm{~g}$ & 16 & $24,67 \mathrm{abc}$ & 28 & $53,04 \mathrm{a}$ & 104 & $26,07 \mathrm{ab}$ & \\
\hline & & & Materi & senesce & te $(\%$ da $\mathrm{m}$ & de for & gem) & & & \\
\hline Triticale & BRS 148 & 28 & $11,18 \mathrm{a}$ & 22 & $11,21 \mathrm{ab}$ & 22 & $12,97 a$ & 84 & $11,79 a b$ & 38,63 \\
\hline Cevada & BRS Marciana & 31 & $12,38 a b$ & 22 & $9,74 \mathrm{ab}$ & 30 & $1,48 b$ & 92 & $7,87 \mathrm{bc}$ & \\
\hline Centeio & BR 1 & 28 & $6,98 \mathrm{~cd}$ & 22 & $4,24 b$ & 22 & $5,77 b$ & 84 & 5,66 cde & \\
\hline & BRS Serrano & 40 & $0,95 \mathrm{ef}$ & 34 & $9,83 \mathrm{ab}$ & 38 & $2,77 b$ & 119 & 4,52 cde & \\
\hline Aveia-branca & UPF 18 & 35 & $8,65 b c$ & 28 & $6,16 \mathrm{ab}$ & 23 & $5,96 b$ & 104 & 6,92 cde & \\
\hline Aveia-preta & UPFA-21 Moreninha & 36 & $5,36 \mathrm{~d}$ & 22 & $10,48 a b$ & 31 & $6,12 b$ & 108 & $7,32 \mathrm{~cd}$ & \\
\hline & Agro-zebu & 36 & $5,51 \mathrm{~cd}$ & 23 & $14,87 a$ & 30 & $15,91 \mathrm{a}$ & 108 & $12,10 \mathrm{a}$ & \\
\hline & Comum & 37 & $6,37 \mathrm{~cd}$ & 24 & 8,24ab & 32 & $5,47 \mathrm{~b}$ & 110 & 6,69cde & \\
\hline Trigo & BRS 277 & 41 & $0,64 \mathrm{f}$ & 22 & $8,66 a b$ & 28 & $1,63 b$ & 122 & 3,64de & \\
\hline & BRS Guatambu & 41 & 4,08de & 23 & $8,20 a b$ & 28 & $0,75 b$ & 122 & 4,34cde & \\
\hline & BRS Tarumã & 42 & $0,95 \mathrm{ef}$ & 23 & $9,51 \mathrm{ab}$ & 34 & $0,12 \mathrm{~b}$ & 127 & 3,52 de & \\
\hline & BRS Umbu & 35 & $0,99 \mathrm{ef}$ & 16 & $5,29 a b$ & 28 & $2,75 b$ & 104 & $3,01 \mathrm{e}$ & \\
\hline
\end{tabular}

Médias seguidas por letras distintas, na coluna, diferem entre si pelo teste de Tukey a 5\% de probabilidade.

Isso pode ser explicado pelo fato de que, no início do desenvolvimento, quando se encontram em estádio meristemático de desenvolvimento, as porções de colmo situadas no topo do dossel apresentam valor nutritivo semelhante às folhas (Queiroz et al., 2000). Esse resultado indica que é possível proceder-se uma desfolha mais intensa no primeiro corte sem que ocorra redução na qualidade da forragem, o que é fundamental no manejo de duplo propósito, pois auxilia na redução da altura do meristema apical (Bortolini, 2000). 
Tabela 3 - Proteína bruta, fibra insolúvel em detergente neutro e em detergente ácido e digestibilidade da matéria seca de genótipos de cereais de inverno de duplo-propósito

\begin{tabular}{|c|c|c|c|c|c|c|}
\hline \multirow[t]{2}{*}{ Espécie } & \multirow[t]{2}{*}{ Genótipo } & \multicolumn{3}{|c|}{ Corte } & \multirow[t]{2}{*}{ Média } & \multirow[t]{2}{*}{ CV (\%) } \\
\hline & & 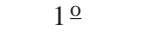 & $2 \underline{0}$ & $3 \underline{0}$ & & \\
\hline \multicolumn{7}{|c|}{ Proteína bruta } \\
\hline Triticale & BRS 148 & 23,19ab & 22,97abc & 19,43 a & $21,86 a b$ & 5,26 \\
\hline Cevada & BRS Marciana & $24,63 a b$ & $22,03 \mathrm{bc}$ & $19,46 \mathrm{a}$ & $22,04 \mathrm{ab}$ & \\
\hline \multirow[t]{2}{*}{ Centeio } & BR-1 & $26,15 a$ & $22,86 a b c$ & $18,75 a b$ & $22,59 a$ & \\
\hline & BRS Serrano & $22,80 \mathrm{~b}$ & $21,78 \mathrm{bc}$ & $14,33 \mathrm{~cd}$ & $19,63 c$ & \\
\hline Aveia-branca & UPF 18 & $23,83 a b$ & $22,50 \mathrm{abc}$ & $18,74 \mathrm{ab}$ & 21,69ab & \\
\hline \multirow[t]{3}{*}{ Aveia-preta } & UPFA-21 Moreninha & $26,05 a$ & $24,13 a b$ & 15,86 bcd & $22,01 \mathrm{ab}$ & \\
\hline & Agro-zebu & $24,55 a b$ & $22,46 a b c$ & $16,55 a b c$ & 21,18 abc & \\
\hline & Comum & $25,04 \mathrm{ab}$ & 23,29abc & $18,93 a b$ & $22,42 \mathrm{a}$ & \\
\hline \multirow[t]{4}{*}{ Trigo } & BRS 277 & $23,15 a b$ & 22,41 abc & 15,93bcd & $20,49 b c$ & \\
\hline & BRS Guatambu & $25,77 a b$ & $20,56 c$ & $13,29 d$ & $19,87 \mathrm{C}$ & \\
\hline & BRS Tarumã & $24,77 a b$ & 22,60 abc & 16,34abcd & $21,24 a b c$ & \\
\hline & BRS Umbu & 23,19ab & $25,53 a$ & $16,99 a b c$ & $21,90 \mathrm{ab}$ & \\
\hline \multicolumn{7}{|c|}{ Fibra insolúvel em detergente neutro } \\
\hline Triticale & BRS 148 & $57,91 \mathrm{ab}$ & $64,02 \mathrm{a}$ & $66,03 \mathrm{bc}$ & $62,65 a b$ & 3,05 \\
\hline Cevada & BRS Marciana & $59,30 a$ & 60,40 abcd & $65,02 \mathrm{bcd}$ & 61,60 abc & \\
\hline \multirow[t]{2}{*}{ Centeio } & BR-1 & $57,21 a b$ & 56,85cde & 62,76 bcde & 58,94cde & \\
\hline & BRS Serrano & $53,78 b$ & 57,69bcde & $68,9 \mathrm{ab}$ & $60,08 \mathrm{bcd}$ & \\
\hline Aveia-branca & UPF 18 & $54,93 a b$ & $55,96 \mathrm{e}$ & 59,19 de & $56,69 \mathrm{ef}$ & \\
\hline \multirow[t]{3}{*}{ Aveia-preta } & UPFA-21 Moreninha & $53,11 b$ & 55,45 e & $58,57 e$ & $55,71 \mathrm{f}$ & \\
\hline & Agro-zebu & $54,96 a b$ & 55,85 e & 61,36 cde & 57,42def & \\
\hline & Comum & $55,11 \mathrm{ab}$ & 56,16 de & 58,18 e & $56,48 \mathrm{ef}$ & \\
\hline \multirow[t]{4}{*}{ Trigo } & BRS 277 & $57,01 \mathrm{ab}$ & 59,11bcde & $66,33 \mathrm{bc}$ & 60,82 abc & \\
\hline & BRS Guatambu & $53,86 b$ & $63,60 a$ & $72,81 \mathrm{a}$ & $63,42 \mathrm{a}$ & \\
\hline & BRS Tarumã & $55,10 a b$ & $61,83 a b$ & $68,24 a b$ & $62,05 a b$ & \\
\hline & BRS Umbu & $52,99 b$ & $60,83 a b c$ & $66,90 \mathrm{abc}$ & $60,24 b c d$ & \\
\hline \multicolumn{7}{|c|}{ Fibra insolúvel em detergente ácido } \\
\hline Triticale & BRS 148 & $21,40 \mathrm{abc}$ & 26,99bcd & 30,26def & $26,21 \mathrm{dc}$ & 5,87 \\
\hline Cevada & BRS Marciana & $25,81 \mathrm{a}$ & 30,31abc & $31,28 c d e f$ & 29,13ab & \\
\hline \multirow[t]{2}{*}{ Centeio } & BR-1 & $23,28 \mathrm{ab}$ & 27,39abcd & 32,69bcd & 27,79abcd & \\
\hline & BRS Serrano & $20,09 \mathrm{bc}$ & $25,78 \mathrm{~cd}$ & $36,44 a$ & 27,43abcd & \\
\hline Aveia-branca & UPF 18 & $24,09 a b$ & $23,46 \mathrm{~d}$ & 30,51def & $26,02 d$ & \\
\hline \multirow[t]{3}{*}{ Aveia-preta } & UPFA-21 Moreninha & $21,14 \mathrm{abc}$ & $26,25 \mathrm{~cd}$ & 30,48def & $25,95 d$ & \\
\hline & Agro-zebu & $22,91 \mathrm{ab}$ & 27,68abcd & $28,38 f$ & $26,32 \mathrm{~cd}$ & \\
\hline & Comum & $23,08 a b$ & 28,05 abcd & 28,93 ef & 26,68bcd & \\
\hline \multirow[t]{4}{*}{ Trigo } & BRS 277 & $24,48 \mathrm{ab}$ & $32,01 \mathrm{ab}$ & 32,21bcde & $29,56 a$ & \\
\hline & BRS Guatambu & $20,44 b c$ & $32,73 a$ & $35,07 \mathrm{ab}$ & $29,41 \mathrm{a}$ & \\
\hline & BRS Tarumã & $23,03 a b$ & 28,10abcd & 34,71abc & 28,61abc & \\
\hline & BRS Umbu & $17,14 \mathrm{c}$ & 27,52abcd & 31,37cdef & $25,34 d$ & \\
\hline \multicolumn{7}{|c|}{ Digestibilidade estimada da matéria seca } \\
\hline Triticale & BRS 148 & $72,22 \mathrm{abc}$ & 67,88 abc & $65,32 \mathrm{abc}$ & $68,47 a b$ & 1,85 \\
\hline Cevada & BRS Marciana & $68,79 c$ & 65,28bcd & 64,52abcd & $66,20 \mathrm{~cd}$ & \\
\hline \multirow[t]{2}{*}{ Centeio } & BR-1 & $70,76 \mathrm{bc}$ & 67,56abcd & 63,43 cde & 67,25abcd & \\
\hline & BRS Serrano & $73,25 a b$ & $68,81 \mathrm{ab}$ & $60,51 \mathrm{f}$ & 67,52abcd & \\
\hline Aveia-branca & UPF 18 & $70,13 \mathrm{bc}$ & $70,62 \mathrm{a}$ & $65,12 \mathrm{abc}$ & $68,62 \mathrm{a}$ & \\
\hline Aveia-preta & UPFA-21 Moreninha & 72,43abc & $68,44 \mathrm{ab}$ & 65,15 abc & $68,67 \mathrm{a}$ & \\
\hline & Agro-zebu & $71,05 \mathrm{bc}$ & 67,33abcd & $66,78 a$ & $68,39 a b$ & \\
\hline & Comum & $70,91 \mathrm{bc}$ & 67,05abcd & $66,36 a b$ & 68,10 abc & \\
\hline Trigo & BRS 277 & $69,83 \mathrm{bc}$ & $63,96 \mathrm{~cd}$ & 63,80bcde & $65,86 \mathrm{~d}$ & \\
\hline & BRS Guatambu & $72,98 a b$ & $63,40 \mathrm{~d}$ & $61,57 \mathrm{ef}$ & $65,98 d$ & \\
\hline & BRS Tarumã & $70,96 \mathrm{bc}$ & 67,00abcd & 61,86def & 66,60bcd & \\
\hline & BRS Umbu & $75,54 a$ & 67,45 abcd & 64,46abcd & $69,15 \mathrm{a}$ & \\
\hline
\end{tabular}

Médias seguidas por letras distintas, na coluna, diferem entre si pelo teste de Tukey a 5\% de probabilidade.

Os maiores valores de FDN do primeiro corte, obtidos para triticale BRS 148, centeio BR 1 e cevada BRS Marciana, podem ser atribuídos, em parte, à maior participação de material senescente. No segundo e terceiro cortes, devido à maior participação de colmos na massa de forragem, foi possível observar-se correlação positiva entre este componente e os teores de FDN ( $\mathrm{r}=0,48 ; \mathrm{P}=0,0032)$. Nesta situação pode-se preconizar uma altura de corte ou pastejo mais elevada, em virtude da diminuição do valor nutritivo do estrato inferior das plantas, com maiores proporções de 
colmos, e visando evitar a remoção do ponto de crescimento. $\mathrm{O}$ aumento dos valores de FDN no segundo e terceiro cortes, em relação ao primeiro, confirma as afirmações feitas por Blaser (1964), de que com o avanço do estádio de desenvolvimento da planta, aumenta o conteúdo da parede celular. Os valores médios de FDN situaram-se próximos ao limite descrito por Van Soest (1965), que considera teores acima de 55-60\% de constituintes de parede celular como limitantes do consumo de forragem. Moreira et al. (2007), em plantio direto sobre palhada de milheto e sorgo sudão, no estado de São Paulo, obtiveram médias entre 51,76 e 60,52\% de FDN, para aveia e triticale, respectivamente. Cecato et al. (2001) observaram valores entre 38,79 e 45,44\% em genótipos de aveia, submetidas a dois cortes, no estado do Paraná, inferiores aos do presente trabalho. Bartmeyer (2006), na mesma região e avaliando o genótipo de trigo BRS 176 em pastejo, de 50 a 95 dias após a emergência, obteve valores entre 45,54 e 62,66\% de FDN, respectivamente.

Para a FDA verificou-se comportamento similar ao da FDN com a sucessão dos cortes (Tabela 3). Os menores valores de FDA foram observados no trigo BRS Umbu, as aveias e os genótipos de centeio. Este resultado pode ser explicado pela menor participação de material senescente, que apresenta altos teores de lignina (Ribeiro et al., 2008). Foi observada correlação, embora baixa, entre material senescente e FDA $(r=0,30 ; \mathrm{P}<0,0001)$. Os valores médios observados no presente trabalho ficaram dentro do preconizado para que não haja restrição no consumo de forragem. Segundo Nussio et al. (1998), forragens com valores de FDA em torno de $40 \%$ ou mais, acarretam redução no consumo, além de apresentar baixa digestibilidade. Os valores observados no presente trabalho foram semelhantes aos relatados por Bartmeyer (2006) para o trigo BRS 176, que obteve valores entre 24,17 e $32,98 \%$ de FDA, em pastejo contínuo com bovinos de corte.

A digestibilidade da MS, no entanto, teve comportamento inverso ao observado para a FDN e a FDA, com diminuição dos valores no decorrer dos cortes (Tabela 3), o que confirma a tendência descrita por Van Soest (1994) de que, à medida que a planta se desenvolve, as frações fibrosas aumentam, enquanto o teor proteico e a digestibilidade diminuem. Essa redução está relacionada ao espessamento e lignificação da parede celular (Wilson, 1997).

Os maiores valores foram observados nos genótipos de aveia e de centeio, e para o trigo BRS Umbu. Estes genótipos também foram os que apresentaram os menores teores de fibra, ressaltando a associação encontrada entre a DMS e a FDN ( $r=-0,83$; $\mathrm{P}<0,0001)$ e com a FDA ( $r=-0,94$; $\mathrm{P}<0,0001)$. Comparando-se as espécies, não foram observadas diferenças, em virtude da variabilidade existente entre genótipos das mesmas espécies, especialmente para o trigo.

De acordo com os coeficientes de digestibilidade obtidos neste trabalho, as forrageiras apresentam boa qualidade. Segundo Leng (1990), a forragem é considerada de baixa qualidade com valores de digestibilidade inferiores a 55\%, associados a teores de proteína bruta menores que $8 \%$.

Os valores obtidos assemelham-se aos observados por Roso et al. (2000), que, trabalhando com a mistura de aveia e azevém sob pastejo exclusivo, encontraram valor médio de $61 \%$. Moreira et al. (2007) observaram coeficientes de digestibilidade entre 77,94 e 78,04\% para a aveia-preta e entre 64,33 e 67,35\% para o triticale sob regime de corte, enquanto Moreira et al. (2005) encontraram digestibilidade média de 60,6\% pesquisando as aveias São Carlos, UFRGS7, UPF87111, UPF86081 e Preta Comum em dois cortes, sendo todos os experimentos conduzidos em Jaboticabal, São Paulo. Com relação aos trigos, os valores encontrados foram inferiores aos relatados por Hastenpflug (2009), que trabalhando com diferentes genótipos de duplo-propósito, em cortes simulando pastejo, no Paraná, observou coeficientes de digestibilidade entre 79,45 e 87,49\%, na média de três cortes.

A composição mineral das forragens apresentou pequenas diferenças entre os genótipos testados (Tabela 4). Os maiores teores médios de cálcio foram obtidos para o centeio BR 1, o triticale BRS 148, a aveia-branca UPF 18 e as aveias preta UPFA 21 - Moreninha e Comum. Apesar de baixa, verificou-se associação entre o intervalo entre cortes e os teores deste mineral $(r=-0,33 ; \mathrm{P}=0,004)$. Os maiores valores de fósforo foram encontrados nos trigos BRS Guatambu, BRS Tarumã e BRS 277. Para o magnésio, não foram observadas diferenças no corte inicial, sendo encontradas pequenas variações nos cortes subseqüentes. Os teores médios variaram de 0,23 a $0,26 \%$. Para o potássio, observaram-se diferenças entre os genótipos somente no terceiro corte. Considerando-se os minerais avaliados, houve menor variabilidade no teor de K entre os genótipos.

Comparando-se os valores médios observados nos genótipos para cálcio, fósforo, magnésio e potássio, de 0,$53 ; 0,32 ; 0,18$ e $1,0 \%$, respectivamente, com as recomendações mínimas do NRC (2001), para dieta de vacas em lactação com peso de $500 \mathrm{~kg}$, produção de leite de $20 \mathrm{~kg} /$ dia e consumo de matéria seca de 3\% do peso vivo, pode-se afirmar que a utilização destas espécies forrageiras atende as exigências para os minerais avaliados. 
Tabela 4 - Composição da fração mineral (\% da MS) em genótipos de espécies de cereais de inverno de duplo-propósito

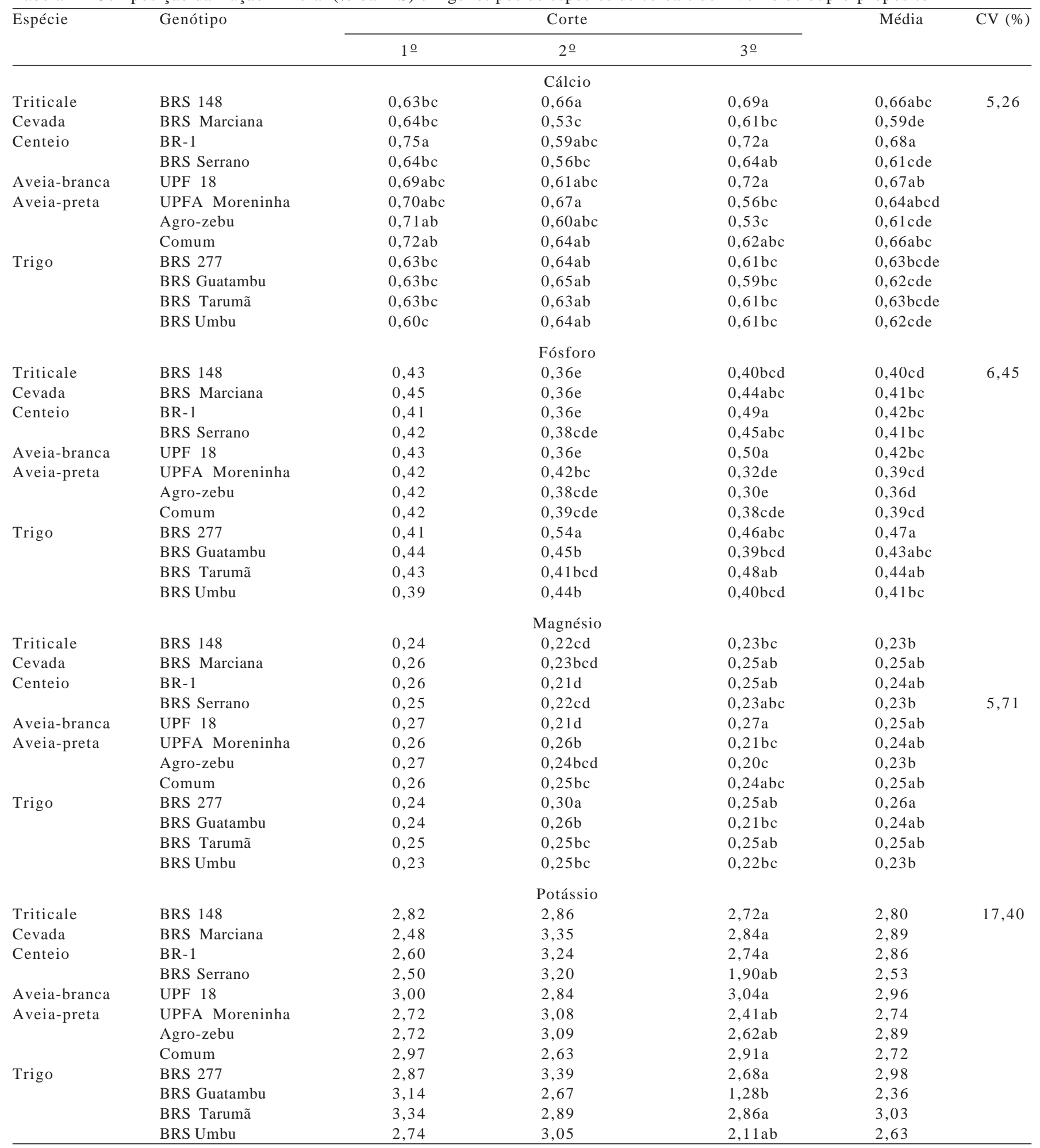

Médias seguidas por letras distintas, na coluna, diferem entre si pelo teste de Tukey a 5\% de probabilidade.

\section{Conclusões}

Existe variação no nutritivo da forragem entre as espécies e os genótipos testados. Os genótipos de aveia produzem forragem com menores teores de fibra e maior digestibilidade.
A composição mineral não tem grande variabilidade entre as espécies e os genótipos de cereais de inverno de duplopropósito. Ovalor nutritivo da forragem dos genótipos é elevado e diminui com o desenvolvimento das plantas, sendo afetado pelas diferenças na composição estrutural do pasto. 


\section{Referências}

BARTMEYER, T.N. Produtividade de trigo de duplo propósito submetido à pastejo de bovinos na região dos Campos Gerais - Paraná. 2006. 70f. Dissertação (Mestrado em Agronomia) - Universidade Federal do Paraná, Curitiba.

BLASER, R.E. Symposium on forage utilization: Effects of fertility levels and stage of maturity on forage nutritive value. Journal of Animal Science, v.23, n.1, p.246-253, 1964.

BOGDAN, A.V. Tropical pasture and fodder plants. New York: Longman, 1977. 475p.

BORTOLINI, P.C. Cereais de inverno submetidos ao corte no sistema de duplo propósito. 2000. 75f. Dissertação (Mestrado em Agronomia) - Universidade Federal do Paraná, Curitiba.

BRUCKNER, P.L.; HANNA, W.W. In vitro digestibility of fresh leaves and stems of small-grain species and genotypes. Crop Science, v.30, n.1, p.196-202, 1990.

CECATO, U.; RÊGO, F.C.A.; GOMES, J.A.N. et al. Produção e composição química em cultivares e linhagens aveia (Avena spp). Acta Scientiarum, v.23, n.4, p.775-780, 2001.

COMISSÃO DE QUÍMICA E FERTILIDADE DO SOLO. Manual de adubação e calagem para os estados do Rio Grande do Sul e de Santa Catarina. 10.ed. Porto Alegre: SBCS-NRS, 2004. 400p.

DEL DUCA, L.J.A.; FONTANELI, R.S. Utilização de cereais de inverno em duplo propósito (forragem e grão) no contexto do sistema plantio direto. In: SIMPÓSIO INTERNACIONAL DO SisTEMA PLANTIO DiRETO, 1., 1995, Passo Fundo. Resumos. Passo Fundo: EMBRAPA-CNPT, 1995. p.177-180.

FONTANELI, R.S.; DURR, J.W.; SCHEFFER-BASSO, S.M et al. Avaliação da qualidade de silagens de milho através da espectrometria de refletância no infravermelho proximal. Revista Brasileira de Zootecnia, v.31, n.2, p.594-598, 2002.

FONTANELI, R.S.; FONTANELI. R.S.; SANTOS, H.P. Rendimento e valor nutritivo de cereais de inverno de duplo propósito: forragem verde e silagem ou grãos. Revista Brasileira de Zootecnia, v.38, n.11, p.2116-2120, 2009.

HASTENPFLUG, M. Desempenho de genótipos de trigo duplopropósito sob diferentes doses de adubação nitrogenada com cortes simulando pastejo. 2009. 66f. Dissertação (Mestrado em Agronomia) - UTFPR, Pato Branco.

LENG, R.A. Factors affecting the utilization of "poor-quality" forages by ruminants particularly under tropical conditions. Nutrition Research Review, v.3, n.3, p.277-303, 1990.

MELLO, L.M.M. Integração agricultura-pecuária em plantio direto: produção de Forragem e resíduo de palha após pastejo. Engenharia Agrícola, v.24, n.1, p.121-129, 2004.

MOREIRA, A.L.; RUGGIERI, A.C.; REIS, R.A. et al. Avaliação da aveia-preta e de genótipos de aveia amarela para produção de forragem e de grãos. ARS Veterinaria, v. 21, Suplemento, 175-182, 2005.

MOREIRA, L.M.; REIS, L.A.; RUGGIERI, A.C. et al. Avaliação de forrageiras de inverno irrigadas sob pastejo. Ciência e Agrotecnologia, v.31, n.6, p.1838-1844, 2007.

NATIONAL RESEARCH COUNCIL - NRC. Nutrient requirements of dairy cattle. 7.rev.ed. Washington, D.C.: 2001. 381p.

NUSSIO, L.G.; MANZANO, R.P.; PEDREIRA, C.G.S. Valor alimentício em plantas do gênero Cynodon. In: PEIXOTO, A.M.; PEDREIRA, C.G.S.; MOURA, J.C. et al. (Eds.) Manejo de pastagens de tifton, coastcross e estrela. Piracicaba: FEALQ, 1998. p.203-242..

PARSONS, A.J.; JOHNSON, I.R.; HARVEY, A. Use of a model to optimize the interaction between frequency and severity of intermittent defoliation and to provide a fundamental comparison of the continuous and intermittent defoliation of grass. Grass and Forage Science, v.43, n.2, p.49-59, 1988.

PHILLIPS, W.A.; RAO, S.C.; DALRYMNPLE, R.L. et al. Annual cool-season grasses. In: MOSER, L.E.L.; BUXTON, D.R.; CASTER, M.D. et al. (Eds.) Cool-season forage grasses Madison: ASA, CSSA and SSSA, 1996. p.781-802.

QUEIROZ, D.S.; GOMIDE, J.A.; MARIA, J. Avaliação da folha e do colmo de topo e base de perfilhos de três gramíneas forrageiras. 2. Anatomia. Revista Brasileira de Zootecnia, v.29, n.1, p.61-68, 2000.

RIBEIRO, J.L.; NUSSIO, L.G.; MOURÃO, G.B. et al. Valor nutritivo de silagens de capim-marandu submetidas aos efeitos de umidade, inoculação bacteriana e estação do ano. Revista Brasileira de Zootecnia, v.37, n.7, p.1176-1184, 2008.

ROSO, C.; RESTLE, J.; SOARES, A.B. et al. Aveia preta, triticale e centeio em mistura com azevém. 1 - Dinâmica produção e qualidade de forragem. Revista Brasileira de Zootecnia, v.29, n.1, p.75-84, 2000.

SCHEFFER-BASSO, S.M.; AGRANIONIK, H.; FONTANELI, R.S. Acúmulo de biomassa e composição bromatológica de milhetos das cultivares comum e africano. Revista Brasileira de Agrociência, v.10, n.4, p.483-486, 2004.

VAN SOEST, P.J. Symposium on factors influencing the voluntary intake of herbage by ruminants: voluntary intake relation to chemical composition and digestibility. Journal of Animal Science, v.24, n.3, p.834-844, 1965.

VAN SOEST, P.J. Nutritional ecology of the ruminant. New York: Cornell University Press, 1994. 476p.

WILSON, J.R. Structural and anatomical traits of forage influencing their nutritive value for ruminants. In: SIMPÓSIO INTERNACIONAL SOBRE PRODUÇÃO ANIMAL EM PASTEJO, 1997, Viçosa, MG. Anais... Viçosa, MG: DZO-UFV, 1997. p.173-208. 